\title{
Intraspecific interactions affect the spatial pattern of a dominant shrub in a semi-arid shrubland: A prospective approach
}

\author{
Carlos Iván Espinosa ${ }^{1}$, Diego P. Vélez-Mora ${ }^{1}$, Pablo Ramón ${ }^{1}$, Elizabeth Gusmán-Montalván ${ }^{1}$, \\ David H. Duncan ${ }^{1,2}$, Pedro F. Quintana-Ascencio ${ }^{1,3^{*}}$ \\ ${ }^{1}$ Universidad Particular Técnica de Loja, Loja, Ecuador, 1101608 \\ ${ }^{2}$ School of BioSciences, University of Melbourne, Parkville, Victoria, Australia, 3010 \\ ${ }^{3}$ Department of Biology, University of Central Florida, Orlando, Florida, USA, 32816 \\ *Corresponding author: pedro.quintana-ascencio@ucf.edu (+1-407-823-1662)
}

\begin{abstract}
Dispersal, physical conditions and biotic interactions contribute to determine the spatial distribution of individuals in plant populations. Much of what we know has been learned from studies that retrospectively posit mechanisms presumed to have generated the observed spatial patterns. Here we present a prospective approach. We start by measuring spatial demographic effects and evaluate if they can generate observed spatial patterns. We evaluated the influence of interactions among conspecifics on vital rates, demography and spatial distribution of Croton aff. wagneri, a dominant shrub in dry Andean ecosystems. Recruitment, survival and growth varied in relation with distance to conspecifics neighbors and with their summed cover. We built a spatial individual-based model and simulated its population dynamics in $30 \times 30 \mathrm{~m}$ plots for a 30 -year period. We compared the predicted spatial pattern from these demographic models with that observed among plants in sixteen independent plots with the same area. Simulated populations mimicked observed spatial patterns, although in plots at high elevations the simulated populations did not reproduce the observed inhibition at small scales. Observed and simulated patterns indicated differences between elevations in maximum aggregation and location of the distances with higher aggregation. We discuss how consideration of critical seed and juvenile stages and interspecific interactions could further improve our understanding of spatial pattern and recommend that these factors be considered in future models.
\end{abstract}

This is the author manuscript accepted for publication and has undergone full peer review but has not been through the copyediting, typesetting, pagination and proofreading process, which may lead to differences between this version and the Version of Record. Please cite this article as doi: 10.1002/pope.1018

This article is protected by copyright. All rights reserved. 
Keywords: Andes, Croton, demography, Ecuador, individual based modeling, spatial point analysis

\section{INTRODUCTION}

The fine scale spatial distribution of individuals within plant populations reflects the interplay between deterministic and stochastic processes such as dispersal, local physical conditions and biotic interactions (Antonovics and Levin 1980; Ripley 1987; Seidler and Plotkin 2006; Lara-Romero et al. 2014; Pereira et al. 2017). At the same time, it is well-documented that population spatial structure itself may influence the quality and intensity of intra- and interspecific interactions, thereby affecting vital rates and population dynamics (Antonovics and Levin 1980; Seidler and Plotkin 2006; North and Ovaskainen 2007). These two facts present a chicken-and-egg dilemma in which some population processes determine fine scale patterns and such patterns in turn affect population dynamics. Whilst it is important to differentiate the influence of biotic interactions on population dynamics and spatial distribution of individual plants in order to better understand population persistence, it has proved difficult to advance in practice due to the spatial and temporal scales involved and lack of demographic information with spatial reference (McIntire and Fajardo 2009; Fedriani and Wiegand 2014).

One effective approach to tackle facets of this epistemological challenge has been the use of spatial point analysis to infer the mechanisms determining the spatial pattern of plants (Wiegand and Moloney 2014). The underlying idea is that the patterns formed by individuals in plant populations can be described with different summary functions at a wide array of spatial scales. These realized patterns can be compared with expectations from a series of "null" models corresponding to the expectations of spatial pattern according to specific biological assumptions. By doing this we can simulate processes taking into consideration plant to plant interactions, dispersal, abiotic heterogeneity or other mechanisms and compare them with the observed patterns. This approach can be considered a retrospective approach in that inference is limited to pairing a contemporary spatial pattern with a biological mechanism which, in retrospect, may have generated it. One can evaluate if biotic interactions affect the relative location of individuals, for example to examine whether competitive processes may be responsible for

regular spatial distribution for some species (Gotelli and McCabe 2002; Jenkins 2006; Adams 
2007) or whether facilitation between species may generate aggregated pattern in the richness of species (Haase et al. 1996; Montesinos et al. 2007; Gimeno et al. 2012).

Many interesting findings have been generated using this retrospective approach. For instance, shifts in level of aggregation according to plant size/age (ontogeny) can be interpreted as evidence of density-dependent mortality (Stoll and Bergius 2005; de la Cruz et al. 2008; Getzin et al. 2008b; Chacón-Labella et al. 2014; Lara-Romero et al. 2017). Such responses can be influenced by species characteristics and by spatial scales (Guo et al. 2005; Song et al. 2011). The inferred effect of neighbors, conspecific or not, are integrated at scales that depend on plant size and habitat, and may change during ontogeny (Bazzaz 1991; Schupp 1995; Espinosa et al. 2015; Lara-Romero et al. 2017). Unfortunately, an unequivocal connection between observed patterns and presumed processes is confounded by the possibility of interactions among factors and reciprocal feedback, which makes prediction hard and the construction of null models sometimes unfeasible.

As far as we know, there is a paucity of prospective studies that instead start by measuring the effects of the interactions at the level of individuals and then evaluate if those data can generate the observed spatial patterns. Such demonstrations will be critical to test and improve our understanding of fine scale spatial population patterns and dynamics. In dry Andean shrublands Croton aff. wagneri influences community structure by sheltering coexisting subshrubs and herbs (Espinosa et al. 2013; Espinosa et al. 2014; Ramón et al. 2016; Lara et al. 2017). Aggregation in Croton varies along altitudinal gradients and with levels of grazing pressure (Espinosa et al. 2014). Previous work has indicated that facilitation and competition may have effects on Croton's population dynamics and spatial structure (Ramón et al. 2016; Lara et al. 2017). However, those studies did not directly measure demographic attributes and their inferences were built indirectly by using a retrospective approaches.

We assessed variation in recruitment, survival, growth and fecundity as function of spatial and temporal variables, particularly as function of distance and density of conspecific neighbors. We used this information to develop an individual based model to evaluate the influence of conspecific interactions, density, site and year on vital rate variation, demography and spatial distribution of Croton. We used this model to simulate population dynamics of Croton and compared the simulated spatial pattern with that observed among plants in plots with the same area. Our models evaluate the extent that the spatial outcome of demographic process as affected by neighboring conspecific location, density, year and site variation mimics observed spatial patterns. The understanding of these phenomena can help to assess the consequences of 
changes in factors affecting plant density and distribution such as human alteration and climatic change.

\section{METHODS}

\section{Study system}

Our study was performed in dry shrublands characteristic of southern Ecuadorian interandean valleys, at Alamala, Catamayo, Loja Province, Ecuador. This ecosystem experiences hot $\left(24.8^{\circ} \mathrm{C}\right.$ mean annual temperature), dry conditions, with an extended dry season (317 mm mean annual precipitation; 57\% of it occurring between February and May; weather station at City Airport in Catamayo 2011-2015; Figure A-1). Water deficit (precipitation less than double the temperature) was prevalent 10 months a year (Espinosa et al. 2013; Figure A-1). The shrubland vegetation is dominated by Croton aff. wagnerii (henceforth Croton), a shrub that can reach around $1.5 \mathrm{~m}$ in height. The patches of Croton form a matrix including sparse xerophytic and spiny vegetation co-dominated by perennials such as Lantana canescens Kunth; Vachellia macracantha (Humb. \& Bonpl. ex. Willd.) Seigler \& Ebinger,Bursera graveolens (Kunth) Triana y Planch., Colicodendron scabridum (Kunth) Seem., and Opuntia quitensis F.A.C. Weber (Ulloa \& Jørgensen 1995; Sierra 1999; Espinosa et al. 2013).

We studied the demography of Croton at two sites on a private property that spans an altitudinal gradient from around $2000 \mathrm{~m}$ to the valley floor at around $1300 \mathrm{~m}$ and covers an area of $12 \mathrm{~km}^{2}$ approx. One site was located at $1400 \mathrm{~m}$ above sea level [thereafter a.s.1.] (359'99" S, $\left.79^{\circ} 26230.933 \mathrm{~W}\right)$ and the other at $1700 \mathrm{~m}$ a.s.1. $\left(3^{\circ} 59^{\prime} 20^{\prime \prime} \mathrm{S}, 79^{\circ} 26263 \mathrm{~W}\right)$; situated $3.8 \mathrm{~km}$ apart on the same slope (Figure A-2). The topography is rugged with moderately steep slopes. A small number of ungulates (donkeys, cows, goats) have been maintained in the property from time to time, but their influence on vegetation structure is mostly noted further down toward the valley floor (Espinosa et al., 2013). Although these animals do not feed on Croton they trample seedlings and small plants and damage plant branches when wandering.

\section{Sampling, analysis and model design}

\section{Demographic data}


We monitored seedling recruitment and survival every second month at each site between June 2014 and June 2016 in 10 permanent pairs of circular plots, each of $0.5 \mathrm{~m}$ diameter. To locate each pair, we generated 10 random points and for each point we located one plot under the nearest canopy of Croton and the paired plot in the nearest neighboring open area at least $25 \mathrm{~cm}$ distant from the Croton canopy ( 2 sites $\times 10$ plots $\times 2$ types $=40$ plots in total). In each plot, we placed a nail adjacent to every new seedling and measured its distance to the main stem of the nearest adult plant. These data were aggregated by intervals post recruitment for analysis because of small sample size.

We estimated seed availability in the soil at each site with the same bimonthly frequency using 10 randomly distributed pairs of $0.5 \times 0.5 \mathrm{~m}$ square plots $(2 \times 10 \times 2=40$ plots $)$. So as not to interfere with the plots used to follow seedling recruitment and survival, these were not located on the same individuals and canopy gaps. For each pair, one plot was placed under Croton canopy and another in open areas between canopies. On each sampling occasion, within each square plot, we randomly choose two cells using a grid of 25 units of $10 \times 10 \mathrm{~cm}$ and collected soil core samples each of $200 \mathrm{~cm}^{3}$. None of the sampled cells was repeated within plot and plot sites were changed each year. The two bimonthly samples from each plot were mixed, bagged and transferred within 24 hours to a laboratory to separate seeds of Croton (diameter of ca. $3 \mathrm{~mm}$ ) using a sieve (2.8 $\mathrm{mm}$ mesh). Seeds were counted and scored visually as either "viable" (those with no apparent damage), "damaged", or "dried-out". For each sample, five seeds were put in Petri dishes with moist filter paper and maintained for four months in a chamber with a 12 -hour light cycle and $25^{\circ} \mathrm{C}$ constant temperature to assess germination. Seeds were discarded if they got moldy.

At each site in June/July 2013 we undertook a census of all established plants $(>10 \mathrm{~cm}$ in height) of any perennial vascular plant species within a $50 \times 70 \mathrm{~m}$ plot (see below and Figure A2 for Croton plants). For each individual, we recorded the height, the longest diameter of the canopy (hereafter "length"), and its perpendicular dimension. The location of each individual in the plot was mapped (see Figure A-2 for Croton plants) using a high-powered GPS and tripodmounted laser distance measure (TS02-5 Total Station, Leica Geosystems), with an estimated accuracy of $<0.5 \mathrm{~cm}$.

To estimate change in plant size, survival and reproductive condition we repeated the census each year from 2014-2016 for all Croton plants in five permanent subplots of variable size (50-200 $\mathrm{m}^{2}$; two and three subplots respectively for a total of $300 \mathrm{~m}^{2}$ in each site). At each 
census, we randomly selected 30 of these plants to estimate the relationship between number of inflorescences and plant size (volume; elliptical area $\times$ height). In May 2013, we counted number of fruits per inflorescence and seed number per fruit from a sample of plants in the larger plots (10 inflorescences per plant, 10 fruits per inflorescence, and 50 plants randomly chosen per site)

\section{Vital rates modeling}

We used a model selection approach based on Akaike's Information Criteria (AICc, Burnham and Anderson 1998; using the R package AICcmodavg; Mazerolle 2006) to identify the most plausible generalized linear models describing vital rate variation as a function of demographic, spatial and temporal drivers. We used binomial distributions and a logit link in the models evaluating seedling and adult survival, Poisson distributions and a logarithm link for seedling count data, and negative binomial distributions and a logarithm link for counts of inflorescences and of seeds in the soil (function glm; R Core Team 2013) and normal distributions and an identity link for individual growth data (function lm; R Core Team 2013). We modeled the number of seedlings recruited as a function of site, and the relative distance to the nearest stem of a reproductive conspecific. We modeled seedling survival as affected by site and the proportional distance from each seedling in the interval between the main stem of their nearest reproductive conspecific plant and the dripline of the canopy of the same focal neighboring plant. We modeled adult survival and annual plant growth per site and year as a function of initial size (for each test we compared the plant height, canopy length and volume and used the best predictor) of the focal plant. Among the variables explaining the variation of final size (growth) we included a linear or quadratic response to the summed canopy area of its conspecific neighbors within a circular plot with $5 \mathrm{~m}$ radius centered on each focal plant. The quadratic models evaluate the possibility of non-linear changes in final plant size with plant crowding. We modeled the number of inflorescences as function of plant size, year and site. We modeled the total number of seeds in the soil as a function of site and sampling occasion. We used the coefficients of the most plausible model for each of these data to simulate Croton population dynamics.

\section{Simulation of population dynamics}

We designed and implemented a spatially explicit, individual-based model to evaluate the effects of intraspecific interactions on population dynamics and spatial structure at each site (Figures 1 and 2). Our model assumes: (1) the effect of current interactions among conspecifics explain the actual spatial pattern of individuals in the populations; (2) these interactions can be simulated as 
an annual Monte Carlo process; (3) other abiotic and biotic effects were negligible. We started each simulation by establishing in the simulated $30 \times 30 \mathrm{~m}$ arena a random number of initial plants ranging from 40 to 180 , that correspond to around $3 \%$ and $15 \%$ of observed number of plants within the actual (where the demographic data were collected) $50 \times 70 \mathrm{~m}$ plots (1295 and 1436 total plants in the sites with high and low elevation respectively). Canopy length for each plant was drawn from a log normal distribution (logarithm of length $4.47 \pm 0.41[94.5 \mathrm{~cm} \pm 1.51]$ for the high elevation sites and $4.59 \pm 0.45[107.2 \mathrm{~cm} \pm 1.57]$ for the low elevation sites). Established simulated plants grew, reproduced and survived following the equations of plausible models describing the effect of size, neighbors, site and annual variation on these vital rates (models evaluated and their parameters are listed in Tables A1-A8 in the supplemental information). Annual variation for plant growth and survival was incorporated giving equal probability for data from each year in the study. We simulated seed dispersal and seedling establishment according to models for these rates (see below and supplemental information). We used the information on the location of the seedlings around the nearest conspecific stem to generate a dispersal kernel, independently per each site, assuming random dispersal in any direction around this plant. Croton probably has a seed bank. However, because seed numbers decayed rapidly between reproductive events, germination occurred during the wet seasons overlapping with seed production, (Figure A-3), and germination rate of seeds from the soil was very low $(<2 \%)$ we allocated seedlings proportionally by fecundity to reproductive plants. Simulated plants were allowed to recruit and interacted with each other for 30 simulated annual intervals. They reached a steady state determined by a ceiling, the summed canopy cover of average size adult plants that filled the neighborhood area around each focal plant (a circular plot of 5 m radius; Figure A-6). We stopped recruitment of new plants around a plant when reaching this ceiling. We completed 199 simulations for each site. At the end of each simulation plants were counted and their degree of spatial aggregation assessed. All simulations and calculations were conducted in $R$ version 3.4.4 (R core team 2013; the complete code can be consulted in the supplemental information)

\section{Spatial point pattern analysis}

We evaluated in 2011-2012, 16 plots $(30 \times 30 \mathrm{~m})$ at two elevation levels: eight at low elevation (between 1400 and $1500 \mathrm{~m}$ a.s.1.) and eight at high elevation (between 1750 and 1900 $\mathrm{m}$ a.s.1.). Half of plots were located on flat ground and other half on steep slopes (approx. $27^{\circ}$ inclination). The plots were $200 \mathrm{~m}$ from each other (see Ramón et al. 2016 for more information). In each plot, all of the Croton individuals were mapped using a compact Electronic Laser Hypsometer TruPulse $360^{\circ}$, which allowed us to calculate the horizontal distance, 
inclination, and azimuth (central angle) from a fixed common vertex to the rooting point of each individual with a precision of $1 \mathrm{~cm}$.

We characterized the magnitude of aggregation of Croton in each plot using a Poisson cluster process (PCP) adjusted to each observed point pattern according to the method of minimum contrast (Diggle 2003, Diggle 2013; Ramón et al. 2016; using the R packages spatstat, Baddeley and Turner 2005 and ecespa, De la Cruz 2008). A PCP describes the formation of a spatial process in two steps. It generates a Poisson pattern of the "reference" points with intensity $\rho$; then each reference point produces a number of "derived" points that follow a Poisson distribution with independent and isotropic positions around each reference point, with mean zero and standard deviation $\sigma$. The aim of fitting the PCP is to estimate $\rho$ and $\sigma$, which measure the magnitude of aggregation and to identify possible differences among populations (Jacquemyn et al. 2007; Lara-Romero et al. 2016). The theoretical K-function for a PCP given by Cressie (1991) is:

$$
K(r ; \rho, \sigma)=\pi r^{2}+\frac{1-e^{\left(-\frac{r^{2}}{4 \sigma^{2}}\right)}}{\rho}
$$

Where $r$ is the radius of the circle (distance) defined in the K-function (Ripley 1976). In this way for each random subplot the model is defined by two parameters: $\rho$, the density of aggregates (cluster centers), and $\sigma$, the average distance of a plant to the center of its cluster (Seidler \& Plotkin 2006). If the value of $\sigma$ exceeds the width of the parcel or $\rho$ exceeds plant density, it can be considered as a random distribution. We present the L-function in the y-axis for interpretation purposes, where $L(r)=\sqrt{K(r) / \pi}-r$ is a standardized version of $\mathrm{K}(\mathrm{r})$ (Besag 1977).

We measured the level of spatial aggregation of Croton plants for each one of 199 simulated plots in each elevation and for the 16 observed plots (each of $30 \times 30 \mathrm{~m}$ ). For each observed plot, we obtained a mean observed $\mathrm{L}(\mathrm{r})$ and test if this one was inside of simulation envelopes. We used a goodness-of-fit (GoF) to assess departures of mean observed $\mathrm{L}(\mathrm{r})$ curves from the simulated demographic model (Loosmore and Ford 2006, Perry et al. 2006). This test was calculated over a range of $0-8 \mathrm{~m}$; the maximum considered prudent for a $30 \mathrm{~m}$ plot size according to Baddeley et al. (2015). We assessed the goodness of fit $(\mathrm{GoF})$ with respect to three functionally important ranges: $0-0.5 \mathrm{~m}$ that defined the area under the canopy of most plants, $0.5-1.5 \mathrm{~m}$ that corresponded to the area of bare soil around most plants that was typically not 
occupied by neighbors and, 1.5-8 $\mathrm{m}$ that corresponded to the area of most interaction among plants in the plot.

\section{RESULTS}

Species attributes and vital rate variation

Croton accounted for $23 \%$ and $26 \%$ of all vascular plant stems (7394 and 8208 stems/ha for Croton) and $36 \%$ and $64 \%$ of the total vascular plant cover in the high and low elevation demography sites respectively. Croton vital rate variation was affected by neighboring plant density and varied among months, years and sites (models and their parameters are listed in Tables A1-A8 in the supplemental information).

The total number of Croton seeds in the soil was higher in the low elevation site, inside the canopy of the plants and after the reproductive events associated with the rainy season in March 2014 and March-April 2015 (800-3000 total seeds $/ \mathrm{m}^{2}$ and $\bar{x}$ ca. 400-650 visually viable seeds $/ \mathrm{m}^{2}$ ) and decreased during the dry months (100-1000 total seeds $/ \mathrm{m}^{2}$ and $\bar{x}$ ca. $20-200$ visually viable seeds $/ \mathrm{m}^{2}$ ). Overall germination of visually viable seeds in laboratory conditions was low (ca.1\%) regardless of time of collection from the soil, year, or site.

Seedling recruitment from soil-stored seed tended to coincide with reproductive events. Presumably both processes respond to available moisture, though only in the site with high elevation was the peak of recruitment clearly associated with the highest moisture (Figure A-3). (Figure A-3). Most observed Croton seedlings recruited inside of the canopy of adult plants (83 $\%$ of 263 total seedlings and $80 \%$ of 111 total seedlings respectively for the study sites with high and low elevation). Seedling recruitment was at its maximum near the canopy drip line (using the largest diameter as reference) in the high elevation site but close to the center of the plants in the site with the low elevation (Figure 3).

Seedling survival during the first two months following recruitment, and under relatively moist conditions, was around 0.6-0.8 (Figure 4, Tables A-1 and A-2). During these first two months, there was no evidence of significant effect of site or distance to nearest adult plant. Under drier conditions in the next two months seedlings survived better under the canopy at the low elevation site and farther from the nearest adult in the high elevation site. During the next 4 6 and 6-8 bimonthly intervals, we found evidence of an effect of site and a weak effect of location on survival with conditions more favorable first at the high elevation site and then 
reversed to the low elevation site. Six-eight months after recruitment average survival probability decreased to 0.4 and its variance increased. Across both sites sample size was too small to build any meaningful models in months $8-12$, so the site averages were used for modeling survival in this interval.

Adult plant survival was generally high (>90\%) except for small plants and in 2015 (Tables A-5 and A-6). Growth in canopy length was highest for smaller adult plants, decreased with conspecific neighbor cover and variable among years and sites (Figure A-4, Tables A-3 and A-4). Number of inflorescences per plant increased exponentially with canopy volume and there was weak evidence that varied among years and sites (Figure A-5, Tables A-7 and A-8). There were less inflorescences per plant volume in 2014 than 2015 or 2016 and in the site with low elevation than in the site with high elevation. We did not find evidence of significant variation in the number of fruits per inflorescence $(\mathrm{z}$-statistic $=-1.5 ; P=0.14)$ or seeds per fruit $(\mathrm{z}$-statistic $=$ $0.3 ; P=0.78)$ among plants within the same site, but we found more fruits per inflorescence (mean \pm standard error (s.e.) per site; $8.7 \pm 3.7$ vs. $5.5 \pm 2.5$ fruits respectively for sites with low and high elevation; $\mathrm{z}$-statistic $=15.5 ; \mathrm{P}<0.001)$ but less seeds per fruit $(2.4+0.04$ vs. $2.9+0.01$ seeds; $\mathrm{z}$-statistic $=-5.1 ; \mathrm{P}<0.001)$ at the site with low elevation.

\section{Conspecific plant interactions and spatial pattern reconstruction}

Observed plots had $821.5 \pm 167.13$ s.e plants in the site with high elevation and $534.75 \pm$ 90.91 s.e plants in the site with low elevation, while the simulated plots had $845.48 \pm 17.87$ in high elevations and $1517.63 \pm 49.02$ in low elevation. Simulated populations mimicked observed spatial pattern in same area plots but slightly exaggerated the degree of aggregation in low elevation sites (Figures 5 and Figure A-6). We found higher variability in the low elevation plots than in high elevation plots in both observed and simulated populations. Goodness of fit analysis among the $30 \mathrm{~m}$ plots did not show differences in spatial structure between simulated and the mean of observed plots (Table 1), except in high elevation plots and at short distances (below $0.50 \mathrm{~cm}$ ), where the simulated populations not reproduced the inhibition showed in observed plots.

\section{DISCUSSION}

Our work indicates that relatively simple demographic models taking into consideration conspecific spatial interactions can reproduce some attributes of the realized spatial distribution of Croton in contrasting conditions. In arid regions plant species occur in patches that are usually 
dominated by few shrub species, which act as ecosystem engineers affecting the ecosystem as a whole (Jones et al. 1994; Badano et al. 2006). Aguiar and Sala (1999) proposed that the demographic processes of these dominant species can determine patch dynamics and consequently plant community structure and composition. Our model included main demographic processes, recruitment, survival, growth and reproduction and the responses of all these vital rates were affected by the spatial structure of neighboring adult plants. These changes in vital rates of Croton, a dominant species in dry Andean ecosystems, were associated with distance to conspecifics, variable dispersal kernels, predicted varying spatial clustering patterns and differences in cluster size between sites. Previous retrospective studies in this ecosystem (Ramón et al. 2016; Lara-Romero et al. 2017) suggested that Croton has an aggregated spatial pattern and that cluster size is context dependent. Ramón et al. (2016) recognized higher clustering among Croton plants at lower elevations than in higher elevations and suggested that these differences were associated with different abiotic conditions such as altitude and slope.

Three main demographic processes have been proposed to explain clustering patterns: limited dispersal, and conspecific and interspecific interactions (i.e. nurse effects; Niering et al. 1963). Recruitment not only depends on primary seed dispersal, but also on multiple biotic and abiotic factors controlling seed germination and seedling establishment (Antonovics and Levin 1980; Seidler and Plotkin 2006; Lara-Romero et al., 2014). We found that Croton seedling densities in the soil were highest near or inside of the plant canopy. These findings are consistent with limited dispersal (Escudero et al. 2004). Croton seeds have a ballochorous dispersal syndrome and their seeds may disperse only few meters (Jara-Guerrero et al. 2015).

Amelioration of abiotic stress under the canopy of adult plants may favor establishment of seedlings around reproductive plants (Antonovics and Levin, 1980; Fajardo and McIntire, 2011, Espinosa et al 2012). Seedling establishment of many species appears to be more frequent under canopies of adult plants of other species, which provide a less stressful micro-environment (Ellner \& Shmida 1981). This association of seedlings and adult plants has been called 'nurse plant syndrome' (Niering et al. 1963) or 'nurse-protege' interaction (Cody 1993). In these interactions, the seedlings benefit from the micro-environment created by the adult plant with presumably little effect on the latter (a form of commensalism that is not necessarily trophic), although other authors have described facultative mutualism in nurse relationships (Pugnaire et al. 1996a, b; Moro et al. 1997; Gibson et al. 1998)

Spatial patterns of recruitment and establishment of seedlings around adult plants were different between sites. In the less dense and more benign high elevation site, seedlings were 
concentrated in the canopy edge, while in the denser and drier low elevation site seedlings were distributed mainly inside of plant canopy. Espinosa et al. (2014) also found that Croton interactions change along the elevation gradient from positive interactions in populations at lower elevation, to neutral-negative in populations at higher elevations. The study site with low elevation was drier and had higher pressure by livestock than the site with high elevation. These results are consistent with the stress gradient hypothesis (Calaway 1997; Bowker et al. 2010), which proposed that the strength of positive interactions increases between plants as the environment becomes less productive and more stressful.

Our simulations, which integrated significant effects of spatial distribution of conspecifics on vital rates into an individual based and spatially explicit model, generated patterns that slightly exceeded observed aggregation in the low elevation site. Neither did they reproduce the degree of inhibition observed in the high elevation site. These shortcomings may be explained by limitations in our sampling and modeling approach. We lacked data on the dynamics of Croton in juvenile stages and consequently our model assumed that the vital rate patterns measured on adult plants were uniformly applicable throughout ontogeny. If there is appreciable temporal variation that affects habitat suitability according to the life stage, which is further modulated by the elevational gradient, then it may have limited our ability to better reconstruct realized patterns via simulation. The dynamics of the juvenile life stages may differ from those of seedlings and adults and may have influenced the overall aggregation (Pereira et al. 2017). Our model was also blind to variation in soil and topographic variables that likely influenced plant vital rates through their effect on moisture and nutriment availability, except to the extent that they may be represented in the elevation contrast. But, we suspect that the more important limitation was that our model did not include the effects that other species may have on vital rate variation and spatial patterns in Croton. These results emphasize that there is more complexity than has typically been assumed in studies where a mechanistic driver of spatial structure is inferred from contemporary pattern instead of being evaluated directly.

Croton vegetation patches play an important role in community diversity and ecosystem function (Cabrera et al. 2013; Espinosa et al. 2013a). Croton patch size and distribution can affect dispersal, recruitment and persistence of itself and many sub-dominant herbaceous and shrub species that require these environments to ameliorate strong seasonal water scarcity. Management changes such as grazing and mining that reduce cover and persistence of Croton populations can have strong negative effects on these ecosystems. These plant communities play a significant environmental role controlling soil erosion and reduction of flood torrents in these steep mountains and their deterioration can cause significant damage in the Andean region. 
Understanding the spatial dynamics of these systems can help to mitigate their deterioration and contribute to its conservation.

\section{ACKNOWLEDGMENTS}

We thank many students and technicians of the Universidad Particular Técnica de Loja for their help in the field and the laboratory. PFQA was partially supported by the Secretaría Nacional de Educación Superior de Ciencia, Tecnología e Innovación - SENESCYT, Gobierno de Ecuador through the program PROMETEO, field work was partially supported by UTPL:

PROY_CNN_0014, PROY_CNN_1260,PROY_CNN_0001 and PROY_CNN_1054. Thanks to MALCA S.A. for access to their property. The suggestions of Adrián Escudero and three anonymous reviewers improved the manuscript.

\section{Literature cited}

Adams DC (2007) Organization of Plethodon salamander communities: guild-based community assembly. Ecology 88:1292-1299

Aguiar MR, Sala OE (1999) Patch structure, dynamics and implications for the functioning of arid ecosystems. Trends in Ecology and Evolution 14: 273-277

Antonovics J, Levin DA (1980) The ecological and genetic consequences of density-dependent regulation in plants. Annual Review of Ecology and Systematics 11: 411-452

Badano EI, Jones CG, Cavieres LA, Wright JP (2006) Assessing impacts of ecosystem engineers on community organization: a general approach illustrated by effects of a high-Andean cushion plant. Oikos 115: 369-385

Baddeley A, Turner R (2005) Spatstat: an R package for analyzing spatial point patterns. Journal of Statistical Software 12: 1-42. URL: www.jstatsoft.org, ISSN: 1548-7660.

Baddeley A, Rubak E, Turner R. (2015) Spatial Point Patterns. Methodology and Applications with R. Boca Raton: CRC Press

Bazzaz FA (1991) Habitat selection in plants. American Naturalist 137: 116-130 
Bates D, Mächler M, Bolker BM, Walker SC (2015) Fitting linear mixed-effects models using lme4. Journal of Statistical Software 67, DOI 10.18637/jss.v067.i01

Besag J (1977) Contribution to the discussion of Dr. Ripley's paper. Journal of the Royal Statistical Society B 39: 193-195

Bowker MA, Soliveres S, Maestre FT (2010) Competition increases with abiotic stress and regulates the diversity of biological soil crusts. Journal of Ecology 98: 551-560

Burnham KP, Anderson DR (1998) Model selection and multimodel inference: A practical information-theoretical approach. Springer Verlag

Cabrera O, Cumbicus N, Naranjo C, Prina A, Rodríguez G, Tinitana F (2013) Plantas del Matorral Seco del sur de Ecuador, Catálogo. Distribución. Usos. Universidad Técnica Particular de Loja, Loja, Ecuador

Callaway RM (1997) Positive interactions in plant communities and the individualisticcontinuum concept. Oecologia 112: 143-149

Chacón-Labella J, de la Cruz M, Vicuña R, Tapia K, Escudero A (2014) Negative density dependence and environmental heterogeneity effects on tree ferns across succession in a tropical montane forest. Perspectives on Plant Ecology, Evolution and Systematics 16: $52-63$

Cody ML (1993). Do Cholla cacti (Opuntia spp., subgenus Cylindropuntia) use or need nurse plants in the Mojave Desert? Journal of Arid Environments 24: 139-154

Cressie N (1991) Statistics for Spatial Data. New York: Wiley \& Sons.

De la Cruz M, Romao RL, Escudero A, Maestre FT (2008) Where do seedlings go? A spatiotemporal analysis of seedling mortality in a semi-arid gypsophyte. Ecography 31 : $720-730$.

De la Cruz M (2008) Métodos para analizar datos puntuales. En: Introducción al análisis espacial de datos en Ecología y Ciencias Ambientales: Métodos y Aplicaciones (eds. Maestre F T, Escudero A and Bonet A), pp. 76-127. Asociación Española de Ecología Terrestre, Universidad Rey Juan Carlos y Caja de Ahorros del Mediterráneo, Madrid.

This article is protected by copyright. All rights reserved. 
Diggle PJ (2003) Statistical analysis of spatial point patterns. Arnold, London.

Diggle, PJ (2013) Statistical analysis of spatial and spatio-temporal point patterns. Third edition. CRC press, Boca Raton

Ellner S, Shmida A (1981). Why are adaptations for long-range seed dispersal rare in desert plants? Oecologia 51: 133-144

Escudero A, Giménez-Benavides L, Iriondo JM, Rubio A (2004) Patch dynamics and islands of fertility in a high mountain Mediterranean community. Arctic, Antarctic, and Alpine Research 36:518-527

Espinosa CI, de la Cruz M, Luzuriaga AL, Escudero A (2012) Bosques tropicales secos de la región Pacífico Ecuatorial: diversidad, estructura, funcionamiento e implicaciones para la conservación. Revista Ecosistemas, 21(1-2)

Espinosa CI, Luzuriaga AL, de la Cruz M, Montero M, Escudero A (2013) Co-occurring grazing and climate stressors have different effects on the total seed bank when compared to the persistent seed bank. Journal of Vegetation Science 24:1098-1107.

Espinosa CI, Luzuriaga AL, de la Cruz M, Escudero A (2014) Climate and grazing control nurse effects in an Ecuadorian dry shrubby community. Journal of Tropical Ecology 30: 23-32.

Espinosa CI, Cruz M, Jara-Guerrero A, Gusmán E, Escudero A. (2015). The effects of individual tree species on species diversity in a tropical dry forest change throughout ontogeny. Ecography 39: 329-337.

Fajardo A, McIntire EJB (2011) Under strong niche overlap conspecifics do not compete but help each other to survive: facilitation at the intraspecific level. Journal of Ecology 99: $642-650$

Fedriani JM, Wiegand T (2014) Hierarchical mechanisms of spatially contagious seed dispersal in complex seed-disperser networks. Ecology 95:514-526

Getzin S, Wiegand T, Wiegand K (2008) Heterogeneity influences spatial patterns and demographics in forest stands. Journal of Ecology 96: 807-820 
Gibson AC, Sharifi MR, Rundel PW (1998) Ecophysiological observations on Lane Mountain milkvetch, Astragalus jaegerianus (Fabaceae), a proposed endangered species of the Mojave Desert. Aliso 17: 77-82

Gimeno TE, Pías B, Martínez-Fernández J, Quiroga DL, Escudero A, Valladares F (2012) The decreased competition in expanding versus mature juniper woodlands is counteracted by adverse climatic effects on growth. European Journal of Forestry Research 131: 977-987

Gotelli NJ, McCabe DJ (2002) Species co-occurrence: A meta-analysis of J.M. Diamond's assembly rules model. Ecology 83: 2091-2096

Guo H, Wang X, Xiao Y (2005) Spatial distribution pattern and fractal analysis of Larix chinensis populations in Qinling Mountain. Journal of Applied Ecology 16: 227-232

Haase P, Pugnaire FI (1996) Spatial patterns in a two-tiered semi-arid shrubland in southeastern Spain. J. Veg. Sci. 7: 527-534

Jara-Guerrero A, de la Cruz, M, Espinosa CI, Méndez M, Escudero A (2015). Does spatial heterogeneity blur the signature of dispersal syndromes on spatial patterns of woody species? A test in a tropical dry forest. Oikos, 124: 1360-1366

Jenkins DG (2006). In search of quorum effects in metacommunity structure: species cooccurrence analyses. Ecology 87: 1523-1531

Jones CG, Lawton JH, Shachak M (1994) Organisms as ecosystem engineers. Oikos 69: 373386

Lara-Romero C, Robledo-Arnuncio JJ, García-Fernández A, Iriondo JM (2014) Assessing intraspecific variation in effective dispersal along an altitudinal gradient: A test in two mediterranean high-mountain plants. PLoS ONE 9(1): e87189.

doi:10.1371/journal.pone.0087189

Lara-Romero C, Gusmán EM, Ramón P, Vélez-Mora D, Espinosa CI (2017). Does size matter? Ontogenetic responses of an Andean shrub to conspecific density-dependence. Perspectives in Plant Ecology, Evolution and Systematics 25: 59-67. 
Mazerolle MJ (2006) Improving data analysis in herpetology: using Akaike's Information Criterion (AIC) to assess the strength of biological hypotheses. Amphibia-Reptilia 27, $169-180$

McIntire EJB, Fajardo A (2009) Beyond description: the active and effective way to infer processes from spatial patterns. Ecology 90: 46-56.

Montesinos D, Verdú M, García-Fayos P (2007) Moms are better nurses than dads: gender biased self-facilitation in a dioecious Juniperus tree. Journal of Vegetation Science. 18: 271-280.

Moro MJ, Pugnaire F.I., Haase, P. \& Puigdefábregas, J. 1997. Mechanisms of interaction between a leguminous shrub and its understorey in a semi-arid environment. Ecography 20:175-184.

Niering WA, Whittaker RH, Lowe CH (1963) The saguaro: a population in relation to environment. Science 142:15-23

North A, Ovaskainen O (2007) Interactions between dispersal, competition and landscape heterogeneity. Oikos 116:1106-1119

Pereira A, Martins FR, Sousa Menezes B, Soares Araújo F. (2017) Is the spatial pattern of a tree population in a seasonally dry tropical climate explained by density-dependent mortality? Austral Ecology doi:10.1111/aec.12556

Pickett STA, Cadenasso ML (1995) Landscape ecology: Spatial heterogeneity in ecological systems. Science 269: 331-334

Pugnaire FI, Haase P, Puigdefábregas J (1996a) Facilitation between higher plant species in a semi-arid environment. Ecology 77: 1420-1426

Pugnaire FI, Haase P, Puigdefábregas J, Cueto M, Clark SC, Incoll LD (1996b) Facilitation and succession under the canopy of a leguminous shrub, Retama sphaerocarpa, in a semi-arid environment in southeast Spain. Oikos 76: 455-464

R Core Team (2013). R: A language and environment for statistical computing. R Foundation for Statistical Computing, Vienna, Austria. URL http://www.R-project.org/. 
Ramón P, de la Cruz M, Chacón-Labella J, Escudero A (2016) A new non-parametric method for analyzing replicated point patterns in ecology. Ecography 39: 001-009

Ripley BD (1976) The second-order analysis of stationary point processes. Journal of Applied Probability 13: 255-266

Ripley BD (1987) An introduction to statistical pattern recognition. In Interactions in Artificial Intelligence and Statistical Methods. Ed. R. Phelps, Gower Technical Press, Aldershot 176-189

Salzman AG (1985) Habitat selection in a clonal plant. Science 228: 603-604

Schupp EW (1995) Seed-seedling conflicts, habitat choice, and patterns of plant recruitment. American Journal of Botany 82: 399-409

Seidler TG, Plotkin JB (2006) Seed dispersal and spatial pattern in tropical trees. PLoS Biology 4: e344. doi:10.1371/journal.pbio.0040344

Sierra R (1999) Propuesta preliminar de un sistema de clasificación de vegetación para el Ecuador continental. Proyecto INEFAN/GEF-BIRF y EcoCiencia, Quito. 193 pp.

Song K, Yu Q, Shang KK, Yang T, Da LJ (2011) The spatial-temporal pattern of historical disturbances of an evergreen broadleaved forest in East China: a dendroecological analysis. Plant Ecology, 212: 313-325

Stoll P, Bergius E (2005). Pattern and process: competition causes regular spacing of individuals within plant populations. Journal of Ecology 93: 395-403

Ulloa C, Jørgensen PM (1995) Árboles y arbustos de los Andes del Ecuador. Department of Systematic Botany. Aarhus University. 264 pp.

Wiegand T, Moloney KA (2014) Handbook of Spatial Point-Pattern Analysis in Ecology. Chapman \& Hall/CRC. Iowa, USA.

This article is protected by copyright. All rights reserved. 


\begin{tabular}{|c|c|c|c|c|c|c|c|c|c|c|c|c|}
\hline Manuscript No. & Manuscript type & Title & $\begin{array}{l}\text { Corresponding } \\
\text { author's name }\end{array}$ & $\begin{array}{l}\text { Corresponding } \\
\text { author's email address }\end{array}$ & $\begin{array}{l}\text { No. of } \\
\text { Figures }\end{array}$ & $\begin{array}{l}\text { No. of } \\
\text { Tables }\end{array}$ & Supporting Information & Received date & Revised date & Accepted date & & Note \\
\hline (記載例) 0013 & Original Article & $x x x x$ & Suzuki, et al & & & 3 & 4 fig: 2 ; table: 1 ; video: 1 & & 30-Jan-18 & 28-Apr-18 & 01-May-18 & $\begin{array}{l}\text { 特別なご指示や連絡事項があれば、こち } \\
\text { らに英語で書いてください }\end{array}$ \\
\hline $\begin{array}{l}\text { POPE-17-00152 } \\
\text { POPF-17-00147 }\end{array}$ & Original Article & $\begin{array}{l}\text { Frog survival and popul } \\
\text { Shelered from the stor }\end{array}$ & II Robert A. Davis, et al. & robert.davis@ecu.edu: & & 2 & $3 \mathrm{~N} / \mathrm{A}$ & & 18-Dec-17 & 15-Jun-18 & 24-Sep-18 & \\
\hline $\begin{array}{l}\text { POPE-17-000147 } \\
\text { POPE-17-00091 }\end{array}$ & $\begin{array}{l}\text { Original Article } \\
\text { Original Article }\end{array}$ & $\begin{array}{l}\text { Sheltered from the stor } \\
\text { Teasing apart cryptic } s p\end{array}$ & $\begin{array}{l}\text { ir Benjamin J.Crain, et al. } \\
\text { p Encarnacăa et al. }\end{array}$ & 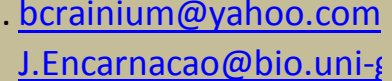 & & ${ }^{2}$ & $\begin{array}{l}4 \text { tables: } 1 ; \text { text: } 1 \\
1 \text { table: }\end{array}$ & & $\begin{array}{l}\text { 29-Novu-17 } \\
\text { 19-Jun-17 }\end{array}$ & $\begin{array}{r}15-\text {-ul-18 } \\
\text { 28-Mav-18 }\end{array}$ & $\begin{array}{l}24-\text { Sep- } 18 \\
24-\text { Sep- } 18\end{array}$ & \\
\hline POPE-17-00114 & Original Article & Demographic conseque & e Nicholas M. Caruso & carusonm@gmail.com & & 5 & 0 files: 3 & & 27-Aug-17 & 25-Jun-18 & 26-Sep-18 & \\
\hline POPE-18-00014 & Original Article & Climatic drivers of pinys & YMadan Kumar Oli & olim@ufl.edu & & 4 & 2 tables: 3 & & 02-Mar-18 & 25-Jun-18 & 24-Sep-18 & \\
\hline $\begin{array}{ll}\text { POPE-17-00108 } \\
\end{array}$ & Original Article & Stress and disturbance & Martínez-Ballesté et al. & andrea.martinez@ib.ur & & 4 & 0 (text: $1 ;$ tables: 5 ; figs: 1 ) & & 04-Aug-17 & 16-Mar-18 & 24-Sep-18 & \\
\hline POPE-17-00136 & Original Article & Surviving background $\mathrm{e}$ & e Ernesto Vega & evega@iies.unam.mx & & 3 & 4 table: 5 ; combined: 1 & & 27-Oct-17 & 26-Jul-18 & 24-Sep-18 & The SI 5 file has been entitled "Supplementary \\
\hline POPE-17-00139 & Original Article & Markov Chain Analysis । & i Andalus T. Punongbaya & apunongbayan@gmail.. & & 9 & 4 combined: 4 & & 03-Nov-17 & 26-Feb-18 & 24-Sep-18 & \\
\hline POPE-17-00140 & Original Article & Synchronized expressio & o Akiko Satake et al. & akiko.satake@kyudai.jp & & 4 & $3 \mathrm{~N} / \mathrm{A}$ & & 04-Nov-17 & 29-Jun-18 & 24-Sep-18 & \\
\hline $\begin{array}{l}\text { POPE-17-00137 } \\
\end{array}$ & Original Article & A population model for & r Ross Booton et al. & r.booton@she eld.ac.ul & & $\overline{7}$ & \begin{tabular}{c|} 
file: 1 ; fig: 1(also included \\
\end{tabular} & & 30-Oct-17 & (03-May-18 & 24-Sep-18 & \\
\hline POPE-18-00005 & Original Article & Coupled population dyr & IV Vanessa Villanova Kuhn & nvanessavk3@gmail.cor & & 4 & 1 file: 1 & & 26-Jan-18 & 23-Jul-18 & 24-Sep-18 & \\
\hline POPE-18-00008 & Original Article & Boom to bust? Implicat & it Michael J. Noad et al. & mnoad@uq.edu.au & & 6 & $5 \mathrm{~N} / \mathrm{A}$ & & 05-Feb-18 & 20-Jun-18 & 24-Sep-18 & \\
\hline POPE-18-00033 & Original Article & Estimating relationship: & : Rick D. Scherer et al. & rick@csp-inc.org & & 4 & $1 \mathrm{~N} / \mathrm{A}$ & & 16-Apr-18 & 03-Aug-18 & 09-Aug-18 & \\
\hline POPE-18-00035 & Original Article & Strong reduction in dial & al Michael Klockmann & Michael.klockmann@ur & & 3 & $4 \mathrm{~N} / \mathrm{A}$ & & 04-May-18 & & 24-Sep-18 & \\
\hline POPE-18-00041 & Original Article & Asexual reproduction cl & cl Thomas Scheuerl & tscheuerl.science@gma & & 3 & 1 file: 1 & & 21-May-18 & 14-Aug-18 & 24-Sep-18 & \\
\hline$\overline{\text { POPE-18-00022 }}$ & Original article & 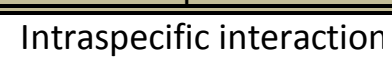 & in Pedro F. Quintana-As & e pedro.quintana-ascenci & & $\overline{5}$ & 1 file: 1 ; text file: 4 & & 19-Mar-18 & 29-Aug-18 & $\begin{array}{ll}16-\text { oct-18 } \\
\end{array}$ & \\
\hline POPE-18-00031 & Original Article & Assessing lek attendanc & ic Peter S. Coates et al. & pcoates@usgs.gov & & 7 & 1 file: 1 & & 15-Apr-18 & 10-Aug-18 & 24-Sep-18 & \\
\hline
\end{tabular}




\section{Figures}

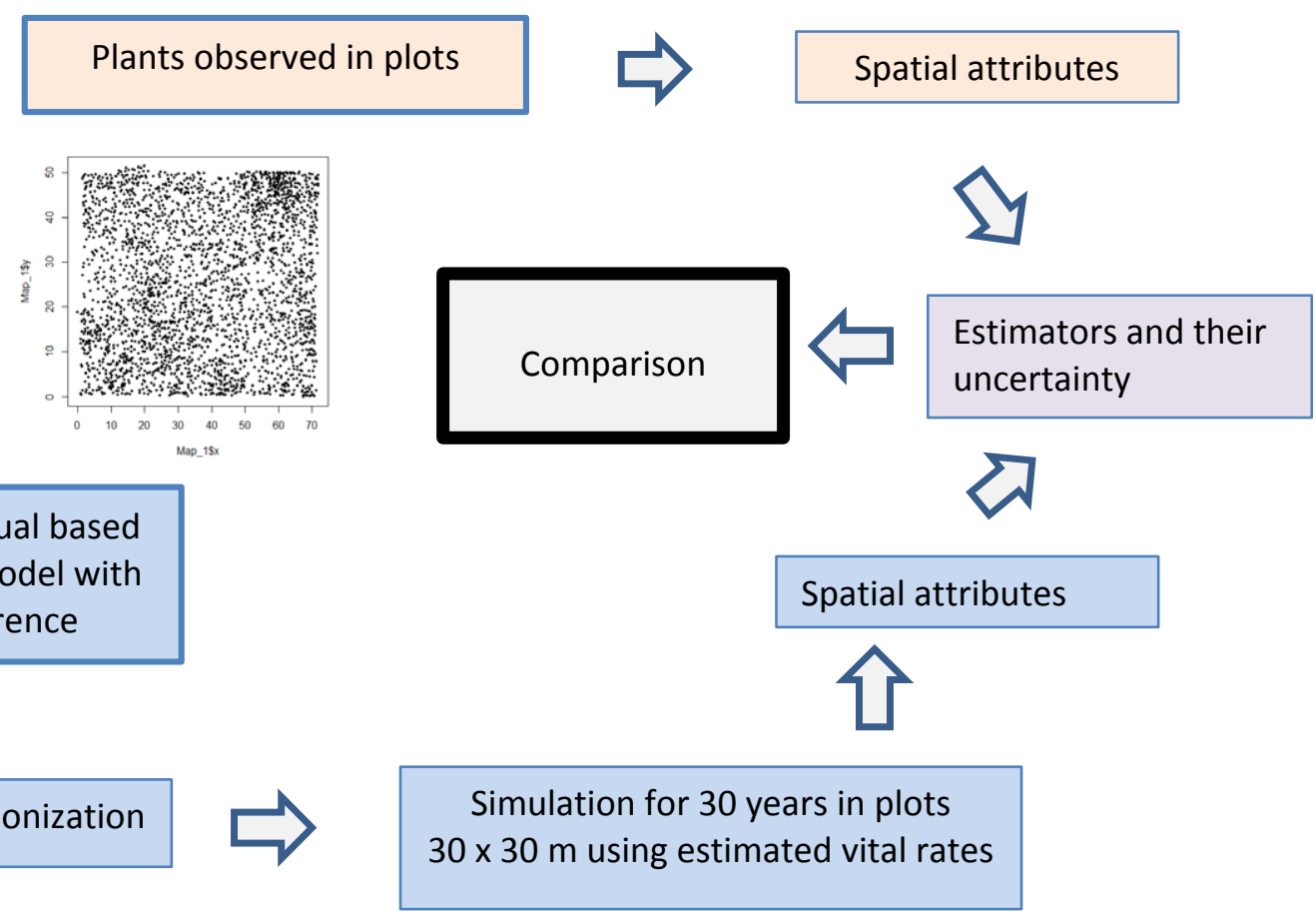

Figure 1. Diagram describing the steps followed to build this evaluation. We started sampling plants within plots and evaluating their spatial attributes. The steps for observed data are in pink, while those of simulated data are in blue. We obtained spatial attributes and made comparisons with simulations after 30 annual time steps ( $n=199$ simulations). 
Randomly introduce adult plants in a $30 \times 30 \mathrm{~m}$ simulation area

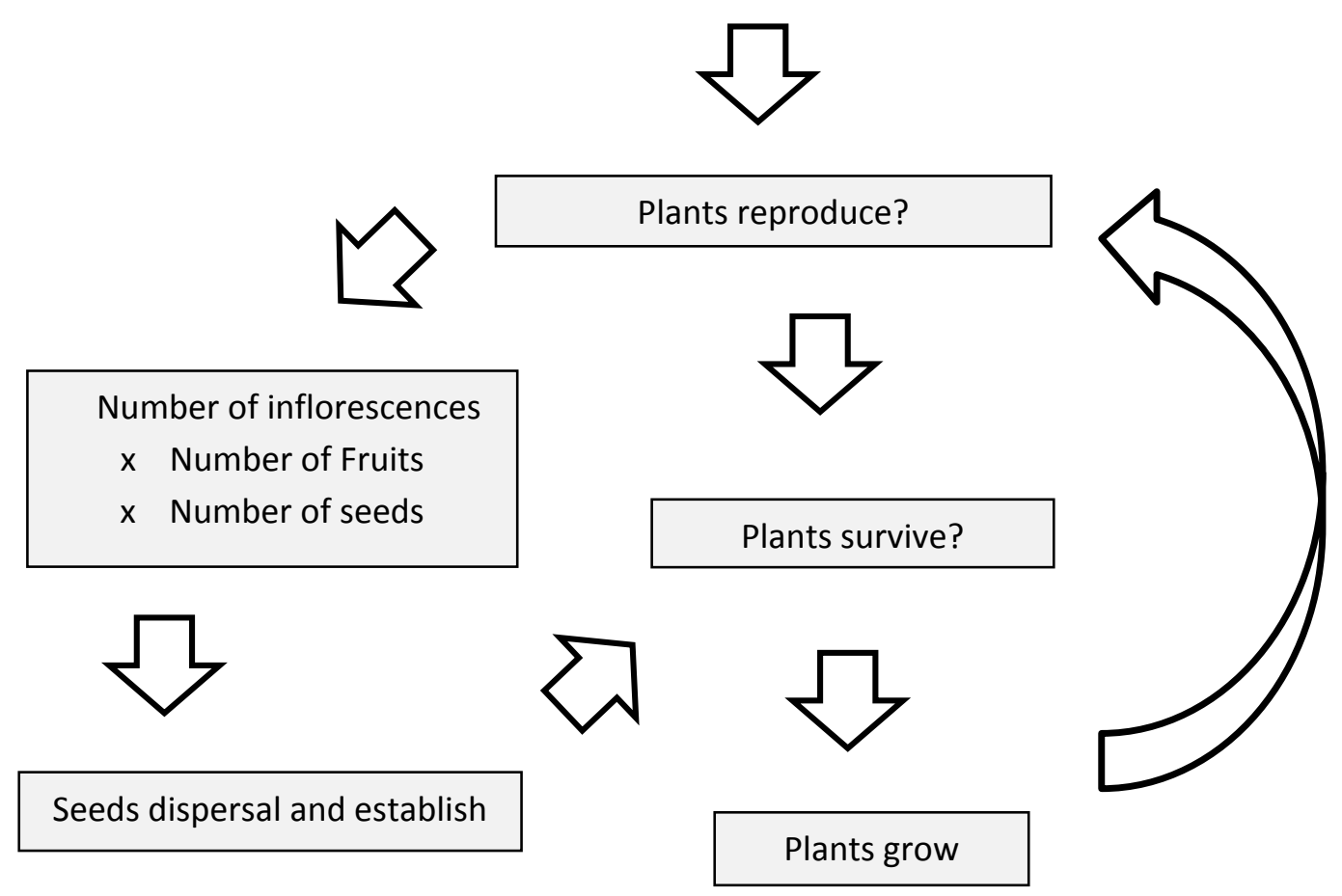

Figure 2. Diagram describing the algorithm of the individual based spatially explicit model. Vital rates or processes in each box were influenced by plant size, number of neighbors, plant distance, site and year depending on the stage (see text and appendix for more details) 
a. Seedlings in high elevation

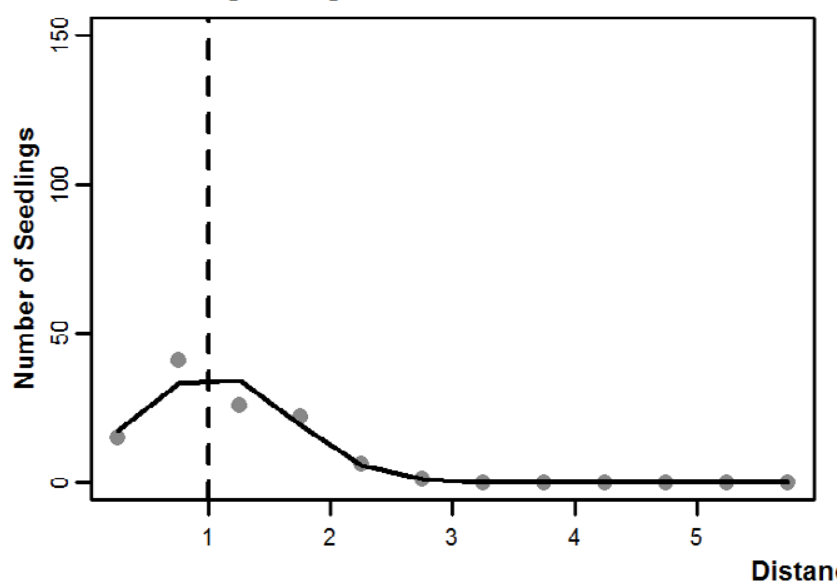

a. Seedlings in low elevation

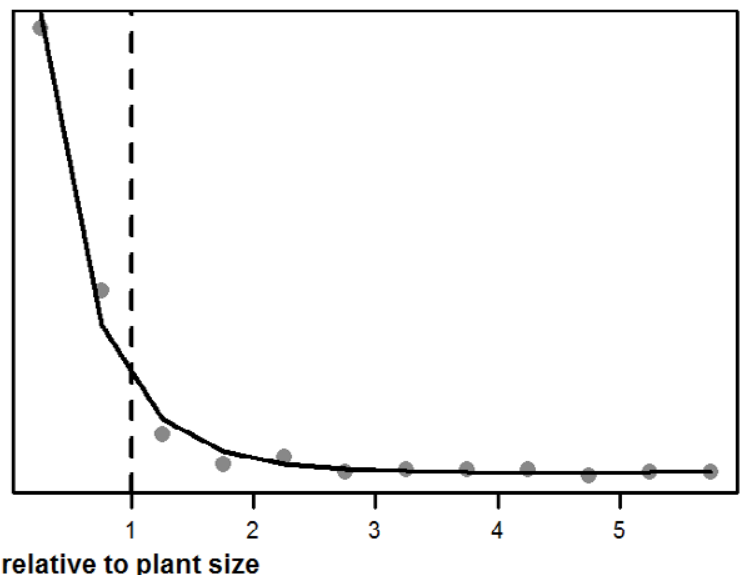

Figure 3. Observed Croton seedlings per $\mathrm{m}^{2}$ at the high elevation site and the low elevation site respectively as a function of the proportional distance to the nearest canopy edge (drip line, marked by the dashed vertical line) of an adult conspecific.

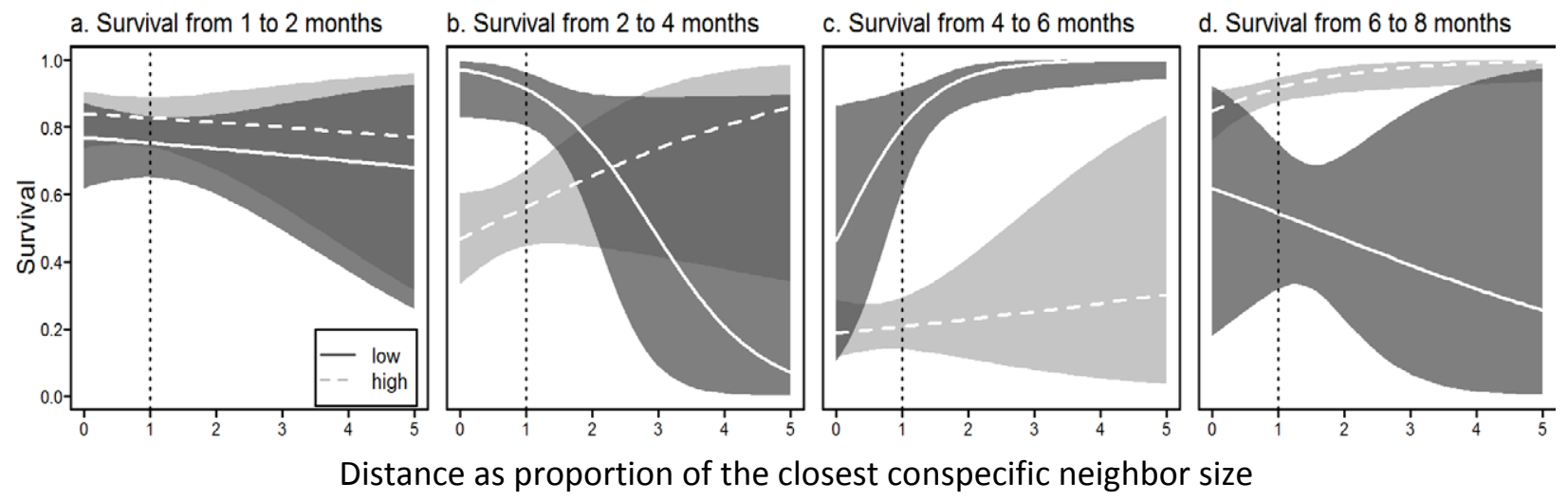

Figure 4. Probabilities (with $95 \%$ CI) of Croton seedling survival at 0-2,2-4, 4-6, and 6-8 months after germination as a function of proportional distance to the drip line of the nearest adult conspecific (vertical discontinuous line), and elevation. 


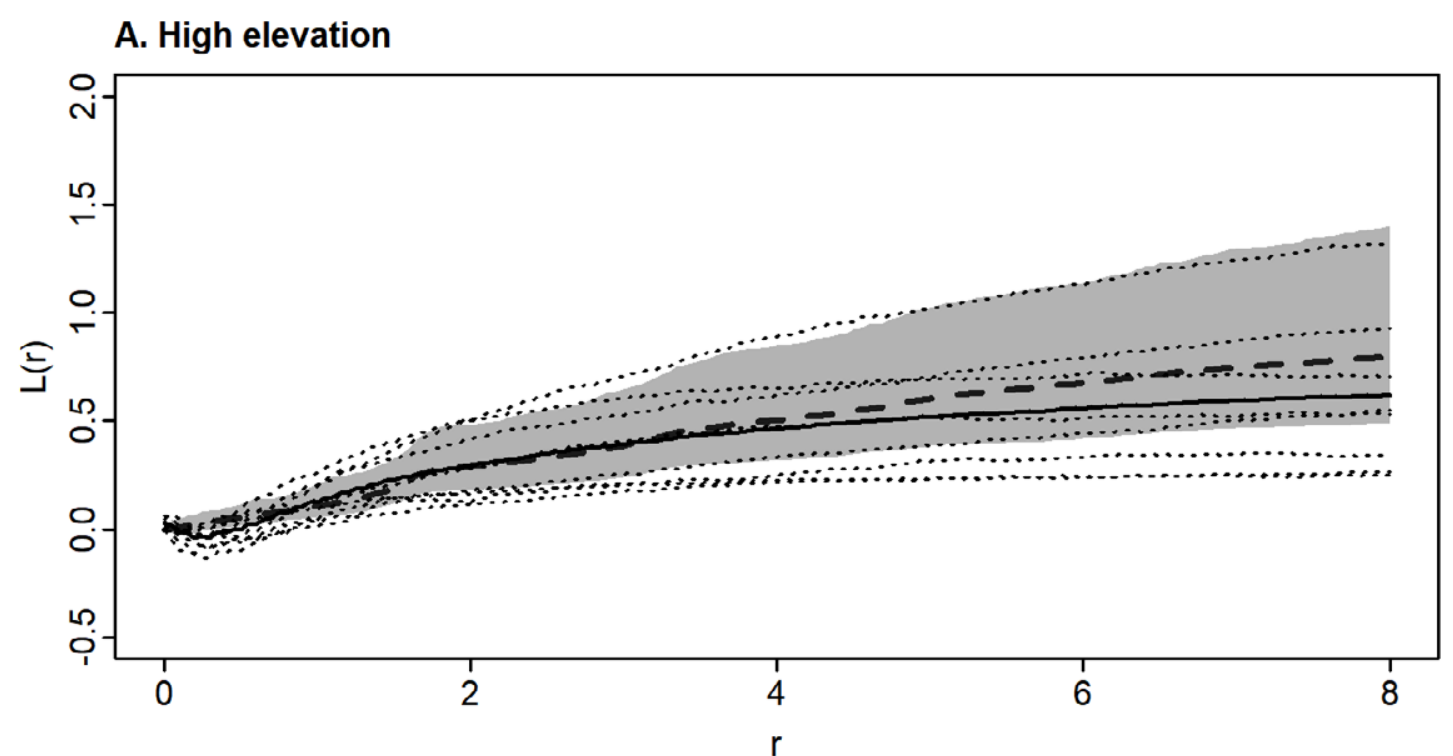

B. Low elevation

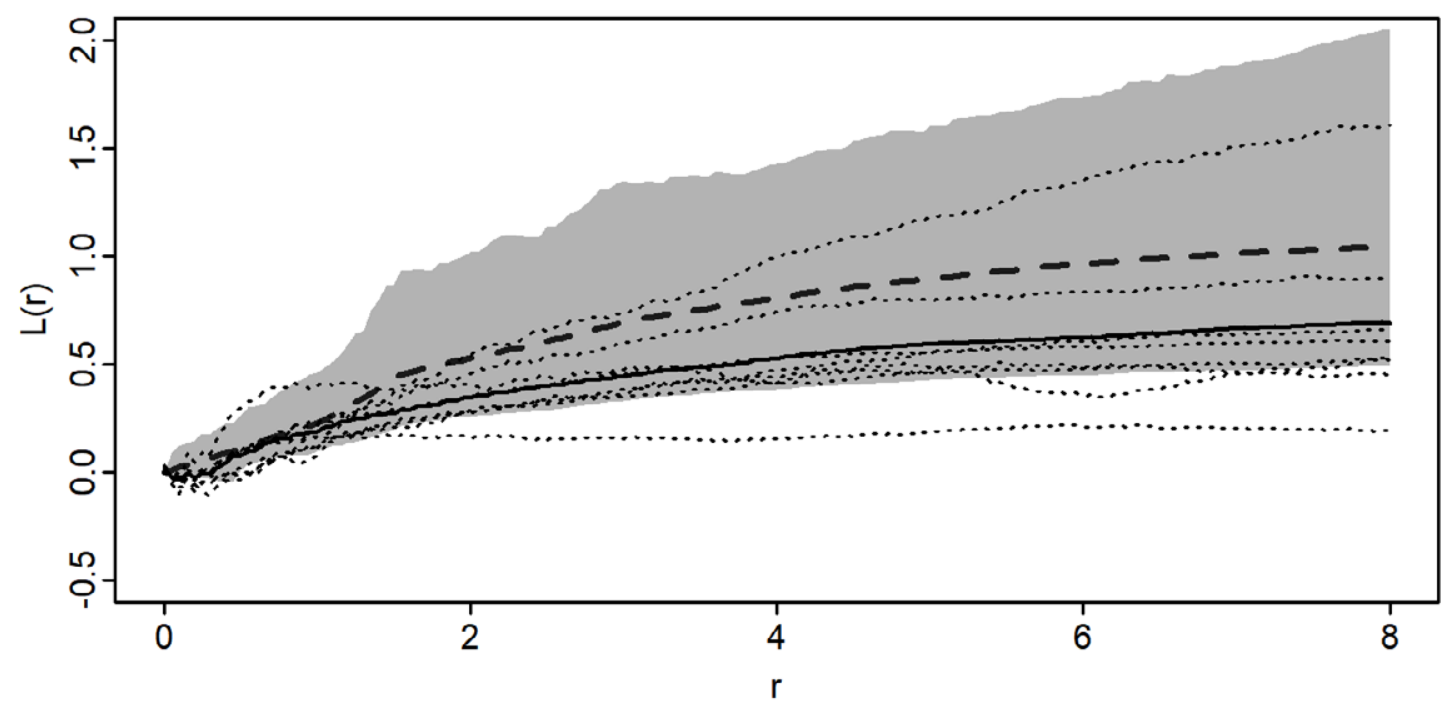

Figure 5. Average L(r)-function for observed Croton point patterns and resulted from spatially explicit demographic simulation for the site with high and low elevation (demographic; $n=199$ simulations). The mean functions are indicated as either dashed lines (observed plants) or continuous lines (for the simulated data). Gray polygons delimit their $95 \%$ CI for simulated data, and dotted thin lines show the eight observed plots. The X-axis scale for $r$ is in meters. 
Tables

\begin{tabular}{|c|c|c|c|c|}
\hline \multicolumn{3}{|c|}{ Low } & \multicolumn{2}{|c|}{ High } \\
\hline Ranges & GOF & p-value & GOF & p-value \\
\hline $0-8$ & 13.0539 & 0.3433 & 1.9063 & 0.6119 \\
\hline $0-0.5$ & 0.0274 & 0.2139 & 0.0291 & 0.0149 \\
\hline $0.5-1.5$ & 0.1170 & 0.5423 & 0.0140 & 0.8109 \\
\hline $1.5-8$ & 12.9386 & 0.3383 & 1.8585 & 0.6119 \\
\hline
\end{tabular}

Table 1. Goodness-of-fit test of mean observed L(r) curves between simulated demographic models and observed plots in low and high elevations. Ranges are measure in meters.

This article is protected by copyright. All rights reserved. 
This article is protected by copyright. All rights reserved. 


\section{University Library}

\section{- M M N E R VA A gateway to Melbourne's research publications}

Minerva Access is the Institutional Repository of The University of Melbourne

\section{Author/s:}

Espinosa, Cl;Velez-Mora, DP;Ramon, P;Gusman-Montalvan, E;Duncan, DH;QuintanaAscencio, PF

Title:

Intraspecific interactions affect the spatial pattern of a dominant shrub in a semiarid shrubland: A prospective approach

Date:

2019-04-01

Citation:

Espinosa, C. I., Velez-Mora, D. P., Ramon, P., Gusman-Montalvan, E., Duncan, D. H. \& Quintana-Ascencio, P. F. (2019). Intraspecific interactions affect the spatial pattern of a dominant shrub in a semiarid shrubland: A prospective approach. POPULATION ECOLOGY, 61 (2), pp.217-226. https://doi.org/10.1002/1438-390X.1018.

Persistent Link:

http://hdl.handle.net/11343/285018 